\title{
Scaling property of ideal granitic sequences
}

\author{
D. Xu ${ }^{1,2,3}$, Q. Cheng ${ }^{1,2}$, and F. Agterberg ${ }^{4}$ \\ ${ }^{1}$ State Key Laboratory of Geological Processes and Mineral Resources, China University of Geosciences, Wuhan (430074), \\ China \\ ${ }^{2}$ Department of Earth and Space Science and Engineering, York University, M3J 1P3, Toronto, Canada \\ ${ }^{3}$ Faculty of Economy, China University of Geosciences, Wuhan (430074), China \\ ${ }^{4}$ Geological Survey of Canada, Ottawa, Canada
}

Received: 14 February 2007 - Revised: 16 April 2007 - Accepted: 23 April 2007 - Published: 8 June 2007

\begin{abstract}
Quantification of granite textures and structures using a mathematical model for characterization of granites has been a long-term attempt of mathematical geologists over the past four decades. It is usually difficult to determine the influence of magma properties on mineral crystallization forming fined-grained granites due to its irregular and fine-grained textures. The ideal granite model was originally developed for modeling mineral sequences from first and second-order Markov properties. This paper proposes a new model for quantifying scale invariance properties of mineral clusters and voids observed within mineral sequences. Sequences of the minerals plagioclase, quartz and orthoclase observed under the microscope for 104 aplite samples collected from the Meech Lake area, Gatineau Park, Québec were used for validation of the model. The results show that the multi-scale approaches proposed in this paper may enable quantification of the nature of the randomness of mineral grain distributions. This, in turn, may be related to original properties of the magma.
\end{abstract}

\section{Introduction}

"Ideal granite" modeling was proposed originally by Vistelius in the 1960s in order to characterize granite crystallization from sequences of rock-forming minerals in granites observed under the microscope. The first attempt to formulate a conceptual stochastic model for examination of granitic rocks was made in Vistelius (1966). A more precise model of granite crystallization from magma was created later, and this became the model for ideal-granite crystallization (Vistelius, 1972). Subsequently, a special version of this model was developed and called the model of "degenerate" ideal granite (Vistelius and Romanova, 1976). Stochastic mod-

Correspondence to: $\mathrm{Q}$. Cheng

(qiuming@yorku.ca) els of ideal, degenerate ideal granite, and two models for metasomatically transformed granites were compared using sequences of grains observed in granitic rocks of Yosemite Valley, California (Vistelius and Harbaugh, 1980). A stock of fine grained potassic granite (Meech Lake aplite) was investigated using a stochastic model for ideal granite (Vistelius, Agterberg, Divi and Hogarth, 1983). In all these models, Markov properties of first and second order of granite sequences were determined from many observations and experiments.

From a non-linear theory point of view, first and second order Markov properties might not be enough to fully quantify the non-linear sequence properties especially for studying the long term memory of a sequence. Scaling issues have been introduced to characterize the distributions and intertwining properties of rock-forming minerals by means of a Markov chain-based discrete multifractal model (Cheng, 1997). Fractal and multifractal models had been developed for characterizing patterns including sequences from a multiscale point of view (Mandelbrot, 1983). Examples of sequences and other forms of objects characterized by scaling or scale invariance properties include clusters of words in English literature (Mandelbrot, 1983; Bohez, 1998), aggregating proteins (Feder et al., 1984), gold films near the percolation threshold (Voss et al., 1982), solar flares (Mogilevsky et al., 2006), ecosystems (Banavar et al., 2007; Martin et al., 2006), cloud boundaries (Lou and Liu, 2007), complex networks (Kim et al., 2007), atmospheric $\mathrm{CO}_{2}$ concentration (Varotosos et al., 2007), large events in driven nonequilibrium systems (Verma et al., 2006), faults on the terrestrial planets (Schultz et al., 2006), size distributions (Benguicui et al., 2006), and vein systems in gold deposit (Sasaki, 2006).

This paper will investigate whether sequences of ideal granite show scaling properties and if so how fractal models can be used to characterize ideal granites? First, it is necessary to define several quantities on the basis of the sequences used for ideal granite modeling that might be analyzed from

Published by Copernicus GmbH on behalf of the European Geosciences Union and the American Geophysical Union. 

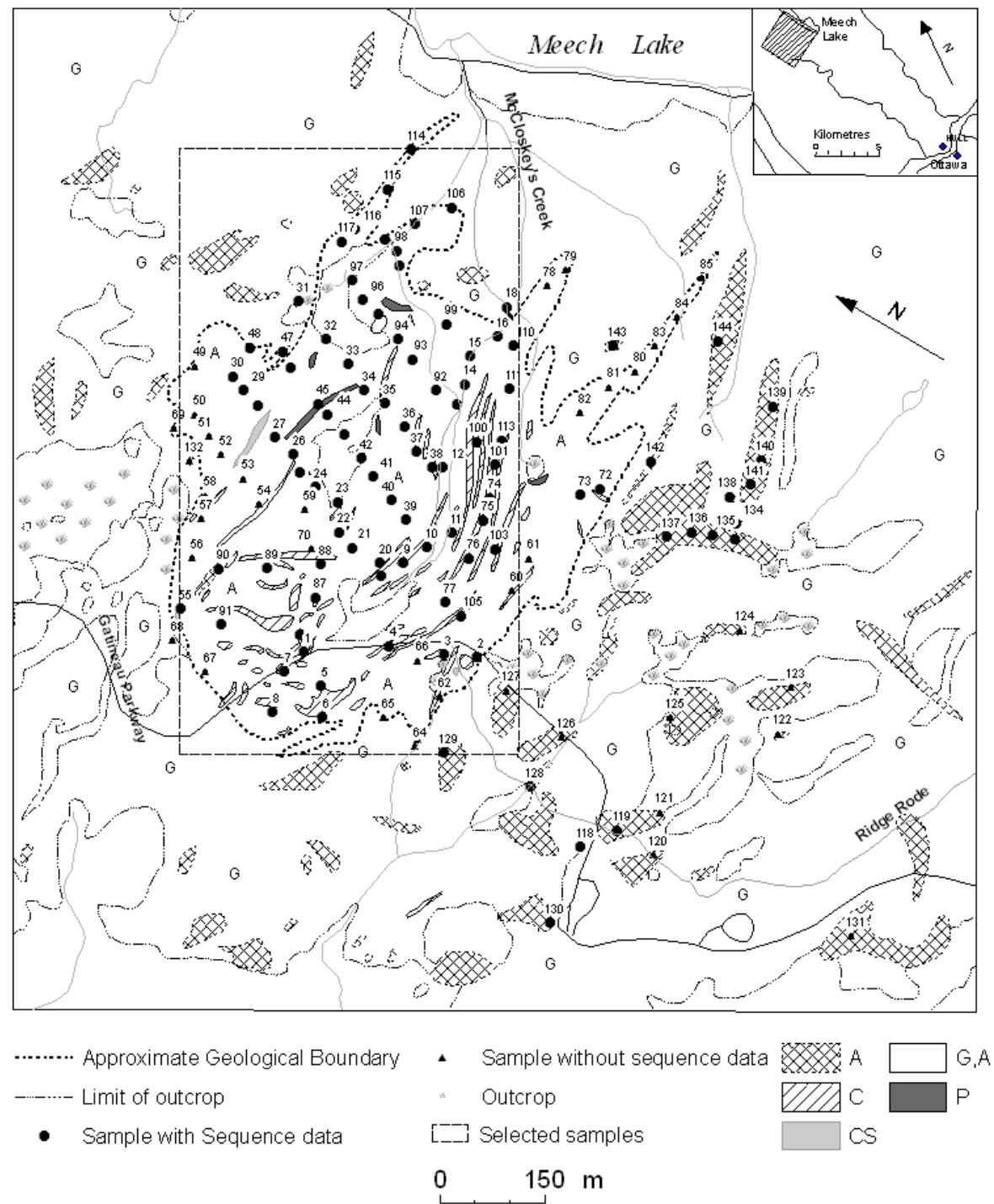

Fig. 1. Study area and sample locations in Meech Lake aplite and surrounding area (after Vistelius et al., 1983). A: Aplite; C: Carbonatite; CS: Calc-Silicate Rock; G: Orthogneiss, Granite Pegmatite, Marble, Calc-Silicate Rock, Biotite Gneiss, Diopside Gneiss; P: Pegmatite (dash lined rectangle shows samples with sequence data used for correlation analysis).

a scaling point of view. Next a standard deviation index will be defined for fractal dimensions of mineral clusters in sequences. This index is demonstrated to be useful for characterizing granite crystallization from magma with variable viscosity. The dataset used in the paper consists of the sequences from Meech Lake granite in Ottawa used originally for the ideal granite study by Vistelius et al. (1983).

\section{Modeling scale invariance property of finite-element sequences}

In order to quantify the scale invariance property of mineral sequence we will introduce a few definitions and notations for modeling scaling property of a general sequences.

\subsection{Definition 1}

Given a real sequence $\left\{x_{i}\right\}_{i=1}^{L}, x_{i} \in S$ and $\| S|| / L \ll 1$, where $S=\left\{a_{1}, a_{2}, \cdots, a_{n}\right\}$ is a finite set of real values and $\|\mathrm{S}\|$ stands for the size of the set, $\|S\|=n$. The size of the set is much smaller than the length of the sequence $(n \ll L)$, so that the sequence can be considered as a long sequence for conducting statistical inference. A k-cluster of $a_{i}$ is defined as $\mathrm{k} a_{i}$ 's following one another continuously in sequence arranged, as in $\cdots a_{j} a_{i} \ldots a_{i} a_{k} \cdots, \mathrm{j}, k \neq i$. The number of elements in the k-cluster is called the length of the cluster. The array between two neighboring clusters of $a_{i}$ is called a void of element $a_{i}$. The length of the void is defined as the number of elements in it plus one. A cluster and a void with 
length $k$ are denoted as $k$-cluster and $k$-void, respectively, in the following discussion. For example, in the sequence "...21113....", " 111 " is a 3-cluster of " 1 ", but " 11 " is not a 2-cluster; in "...211132332112...", the sequence "32332" is a 6-void of " 1 " which is the void of length 6 between a 3 -cluster and a 2 -cluster.

\subsection{Definition 2}

For a given sequence $\left\{x_{i}\right\}_{i=1}^{L}$, if the number of $k$-clusters of element $a_{i}, N\left(c\left(a_{i}\right)=k\right)$, is linearly proportional to the power of the inverse of the length $\mathrm{k}$ of the clusters as $k^{-\alpha_{i}}$, i.e. for any existing $k$ with

$N\left(c\left(a_{i}\right)=k\right) \propto k^{-\alpha_{i}}$

then the sequence is called cluster scaling invariant for $a_{i}$, denoted by CSI; $\alpha_{i}$ is called the invariance index of cluster. If the number of k-voids $N\left(v\left(a_{i}\right)=k\right)$ is linearly proportional to the power of the inverse of the length $\mathrm{k}$ as $k^{-\beta_{i}}$ for any existing $k$

$N\left(v\left(a_{i}\right)=k\right) \propto k^{-\beta_{i}}$

then the sequence is called void scaling invariant for $a_{i}$, denoted by VSI; $\beta_{i}$ is called invariance index of void.

\subsection{Definition 3}

In definition 2, count the number accumulatively as $N\left(c\left(a_{i}\right) \geq k\right)$ or $N\left(v\left(a_{i}\right) \geq k\right)$. If the number is linearly proportional to the power of the length of the cluster or the length of void, then the sequence is called cluster accumulatively scaling invariant or void accumulatively scaling invariant, denoted by CASI and VASI, respectively. Similarly to Eqs. (1) and (2), if the sequence is CASI and VASI for $a_{i}$, then we have the formulae:

$N\left(c\left(a_{i}\right) \geq k\right) \propto k^{\alpha_{i}^{A}}$

$N\left(v\left(a_{i}\right) \geq k\right) \propto k^{\beta_{i}^{A}}$

To distinguish between CSI and VSI, $\alpha_{i}^{A}$ and $\beta_{i}^{A}$ are referred as the invariance indexes for CASI and VASI.

\subsection{Property 1}

If for any $a_{i}$ in the sequence $\left\{x_{i}\right\}_{i=1}^{L}, x_{i} \in S=\left\{a_{1}, a_{2}, \cdots, a_{n}\right\}$ is cluster scaling invariant, and $\alpha_{i}(i=1,2, \cdots, n)$ are the invariance indexes, and then $\alpha_{i}(i=1,2, \cdots, n)$ are correlated due to a closure effect, $\sum_{i} \sum_{k_{i}} k_{i} N\left(c\left(a_{i}\right)=k_{i}\right)=L$.

\subsection{Property 2}

For a cluster scaling invariant and void scaling invariant sequence $\left\{x_{i}\right\}_{i=1}^{L}, x_{i} \in S=\left\{a_{1}, a_{2}, \cdots, a_{n}\right\}, \alpha_{i}$ and $\beta_{i}$ are correlated because for $i=1,2, \ldots, n$

$$
\sum_{k} k N\left(c\left(a_{i}\right)=k\right)+\sum_{m}(m-1) N\left(v\left(a_{i}\right)=m\right)
$$

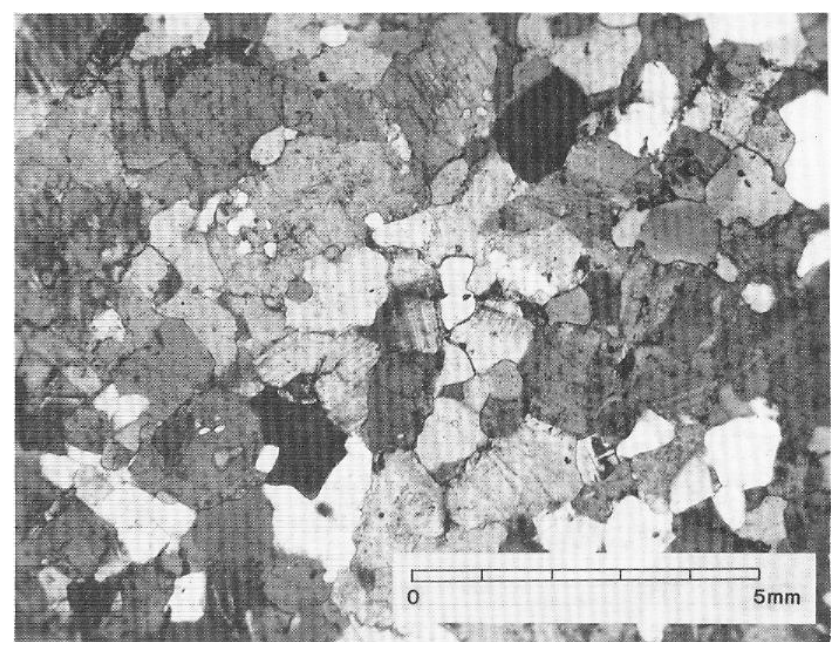

Fig. 2. Typical Meech Lake aplite texture (Vistelius et al., 1983). Sample 73. Nichols crossed. Minerals are mostly Orthoclase $(57.5 \%)$, frequently striped Plagioclase $(15.6 \%)$ and irregularly shaped Quartz (24.2\%; rounded forms).

$$
=\sum_{k} k \cdot k^{\alpha_{i}}+\sum_{m}(m-1) \cdot m^{\beta_{i}}=L+C_{i}
$$

where $C_{i}$ are constants related to the number of elements before the first $a_{i}$ and the number of elements after the last $a_{i}$ in the sequence.

Similar results can be obtained for the accumulative cases, CASI and VASI.

If a sequence $\left\{x_{i}\right\}_{i=1}^{L}, x_{i} \in S=\left\{a_{1}, a_{2}, \cdots, a_{n}\right\}$ shows the CSI property for all elements $a_{i}$, and each cluster or void corresponds to finite invariance indexes $\alpha_{i}$ or $\beta_{i}$, respectively, then these intertwined clusters of elements can be considered as special cases of finite multifractals with measuring unit of cluster length (Cheng, 1997).

\section{Scaling properties of ideal granite sequences from Meech Lake Aplite}

\subsection{Study area and ideal granite sequences}

The study area chosen for this study is the Meech Lake Aplite in the Gatineau Park, Québec, which was studied by Vistelius et al. (1983). The dataset used by Vistelius et al. (1983) for ideal granite modeling is used in the current study. It includes 104 samples collected from the Meech Lake aplite. The study area and locations of samples are shown in Fig. 1. Thin sections were made from these rock samples and sequences of three rock-forming minerals: plagioclase, quartz and orthoclase, were identified under the microscope. An example of photography taken under microscope is shown in Fig. 2. Ideal granite sequences published by Vistelius et al. (1983) are denoted as sequences of three minerals coded as " 1 ", "2" and " 3 ", representing grains of microcline, quartz 

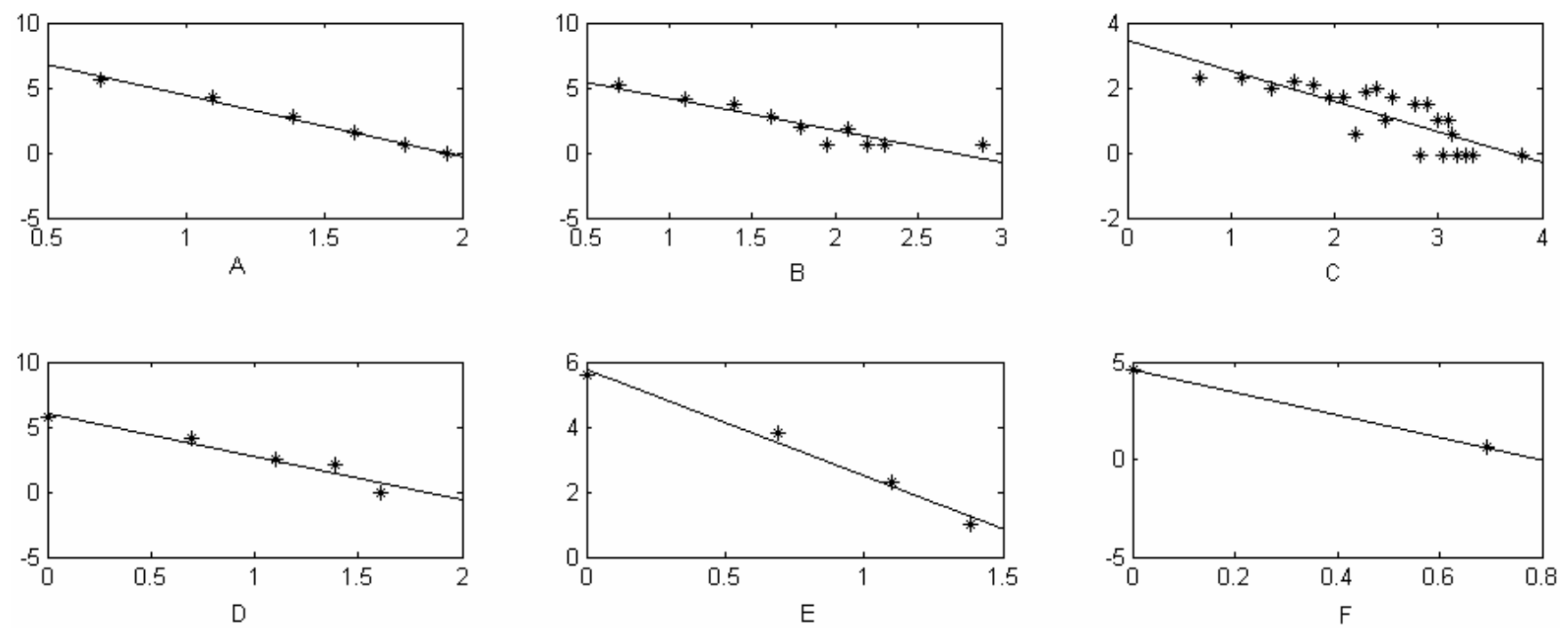

Fig. 3. Test for CSI and VSI for element "2" in the sequence of Sample 3. Plots show the relationships between frequency of clusters and cluster length and between voids and void length obtained from sample 3. (A) to (C) show the results of voids for elements " 1 ", " 2 " and "3", respectively; and (D) to (F) give the results of clusters obtained for elements " 1 ", "2" and "3". Logarithmic transformation is 10 based. Solid lines are fitted by means of least squares. The statistics for these plots are given in Table 1.
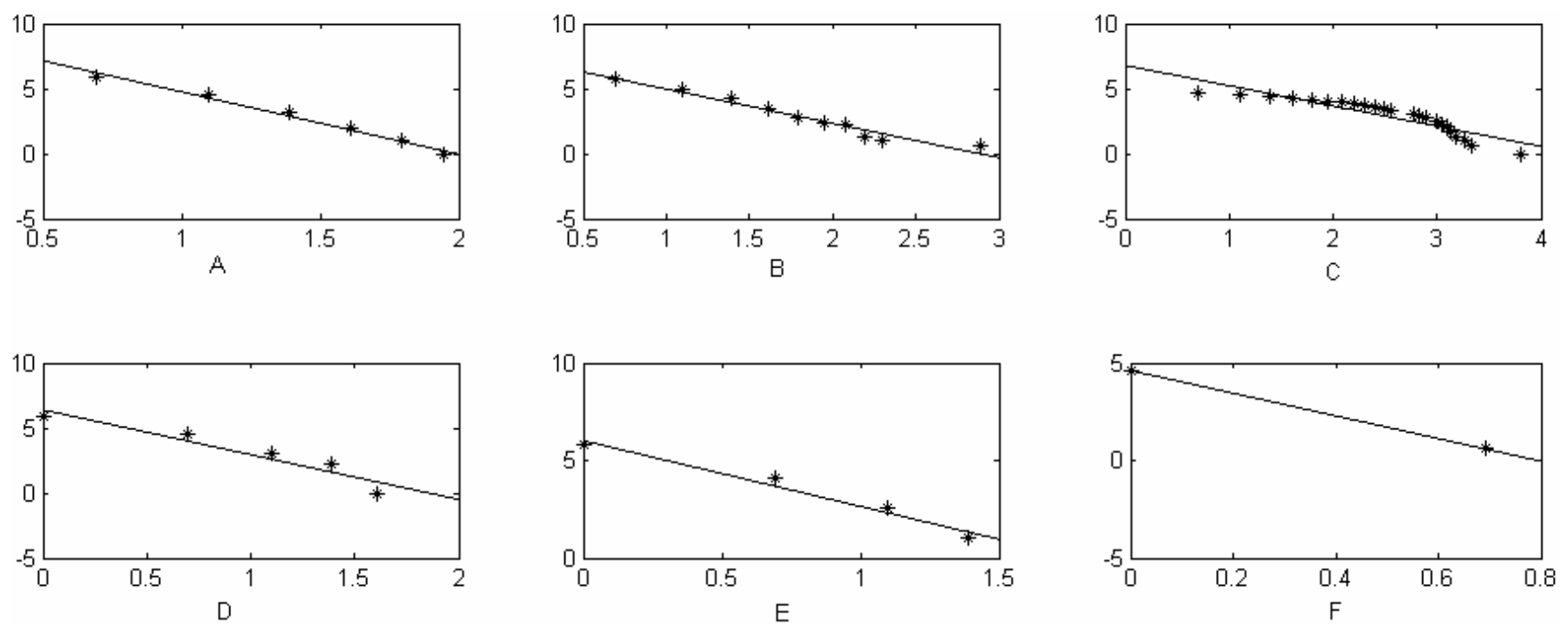

Fig. 4. Test for CASI and VASI for element "2" in the sequence of Sample 3. Plots show the relationships between the accumulative frequency of clusters and cluster length and between accumulative frequency of voids and void length obtained from sample 3. (A) to (C) show the results of voids for elements "1", "2" and "3", respectively; and (D) to (F) give the results of clusters obtained for elements "1", " 2 " and " 3 ". Logarithmic transformation is 10 based. Solid lines are fitted by means of least squares.

and orthoclase, respectively. An example of a sequence of this type is

$$
\text { “...,1,1,3,1,2,2,3,1,1,2;3,3,2,1,3,3,2,1,2,1,2,2,2,..." }
$$

In order to obtain results of statistical significance, the sequences should be long enough. As a rule, subsequences separated by ";" in a sequence should be chosen as those containing no less than 10 grains (Vistelius et al., 1983). The usual sequence length for this analysis is about 1000 and there may be several subsequences. The following sequence is an example taken from sample 3 in the paper by Vistelius et al. (1983).

1212112121122122121212121131211212121121212

$131221221121212213112121212 ; 2312132121211112$

12212;21312122311212113212221212121212312212

12122211121212121321212121121321123211221212 
$1312131211121313111312121212121 ; 2121121212121$

2111212112122121222321312212122123121311321; 12131232131211121112113113122123121213121112 1222112221221312121121212121212211213121121 2122122123221112211311112131211211312112112 1111212131212121212113212122121321321212121 22121212;12121212121321123121212121212121312 2121221121212121212121231212121221111222211 $33221 ; 21211211211211313221121221121311212212$ $113111223112122 ; 121232121213212132121111232$ 22212121212312121;21221212121221213113211212 2113121111311131311111321213121321212112131 $12222111131121 ; 12121213211212132121313131212$ 2121311212122121212211323213112212121312131 22213121212121311113213121212221213122121212 1332221131311213;21212121122121212221312121 12121122121212212131212112211222122112213121 212121212;121222131121312121213212111312122 $131312112123113121212 ; 1213122121322121211221$ 23112;1121111212112132313121213113131221212 11211312212121113121112112212121212112312113 2121312112121212112131213121212;

These data were used to form Markov transition probability matrix for characterizing first and second order Markov properties. From the results the samples were classified into ideal granites and non-ideal granites. The former show high degree of randomness in granite crystallization which might be interpreted as the magma having had high viscosity due to relatively low concentration of calcium (plagioclase percentage) and high potassium and sodium concentration (orthoclase).

\subsection{Scaling analysis of ideal granite sequences}

To validate the power-law models (1) and (2) with the ideal granite sequences, the following preprocessing calculations were conducted:

1. Connecting all sequences observed in a sample by omitting ";" to form one long sequence, which is equivalent to reading the grains of a section in a zigzag way. This should be reasonable under the assumption that granite textures are isotropic.

2. To avoid edge effects, the beginning before the considered element appears and ending after the last considered element disappears are regarded as two voids of the element. For instance, considering grain " 3 " in the sample above, "12121121211221221212121211" before the first " 3 " and "121212" after the last " 3 " are regarded as a 27 -void and a 7 -void, respectively. This is reasonable since there is no significant error if the sequence is sufficiently long.

3. Linear functions are fitted to the log-transformed data, $\log \left[N\left(c\left(a_{i}\right)=k\right)\right]$ and $\log (k)$ for cluster analysis and

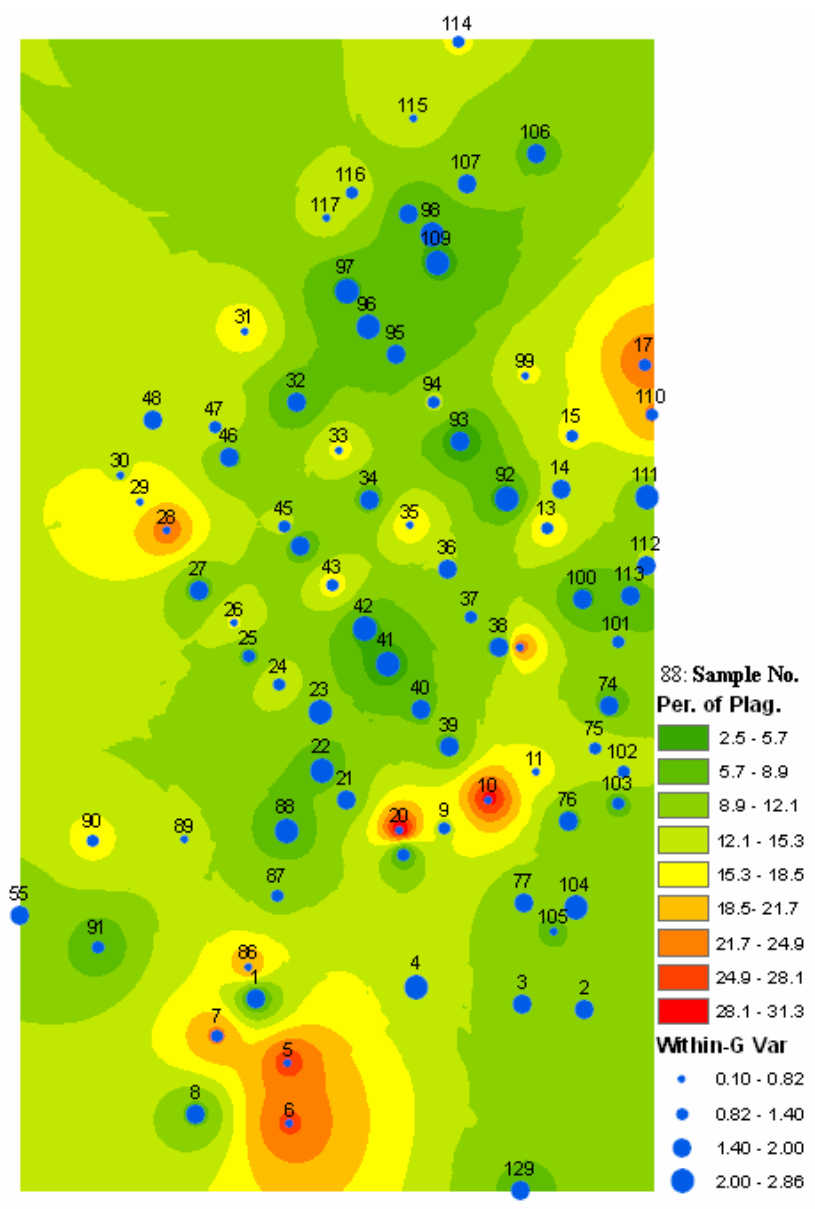

Fig. 5. Map showing the spatial relationship between distributions of percentages of plagioclase in granite and within-group variances of void scale invariance indexes calculated from the sequences from samples in Meech Lake aplite for the area indicated in Fig. 1. The background patterns are created from the percentage values of plagioclase using inverse distance weighting interpolation method with searching distance $1.2 \mathrm{~km}$, and minimum number of points 12 . The size of dots represents the level of within-group variance of void scaling invariance index calculated for three minerals.

$\log \left[N\left(v\left(a_{i}\right)=k\right)\right]$ and $\log (k)$ for void analysis, by means of least squares. The slope of the straight-line gives the value of $\alpha_{i}$ or $\beta_{i}$. Correlation coefficients and $t$ statistics related to this linear regression are calculated for validation of the power-law models (1) and (2).

To illustrate the process we show the results for the void and cluster analysis of element " 2 " in samples 3 in Tables 1 and 2 , respectively. Based on the data from Table 1 we can produce plots on $\log -\log$ paper. If the values of $\log N(v=k)$ and $\log (k)$ show linear trend then these data can be fitted with straight-lines by means of least squares. The correlation coefficients and t-statistics can be calculated from the least square fittings. For example, Figs. $3 \mathrm{~b}$ and e show the results for void and cluster for element "2" calculated from 

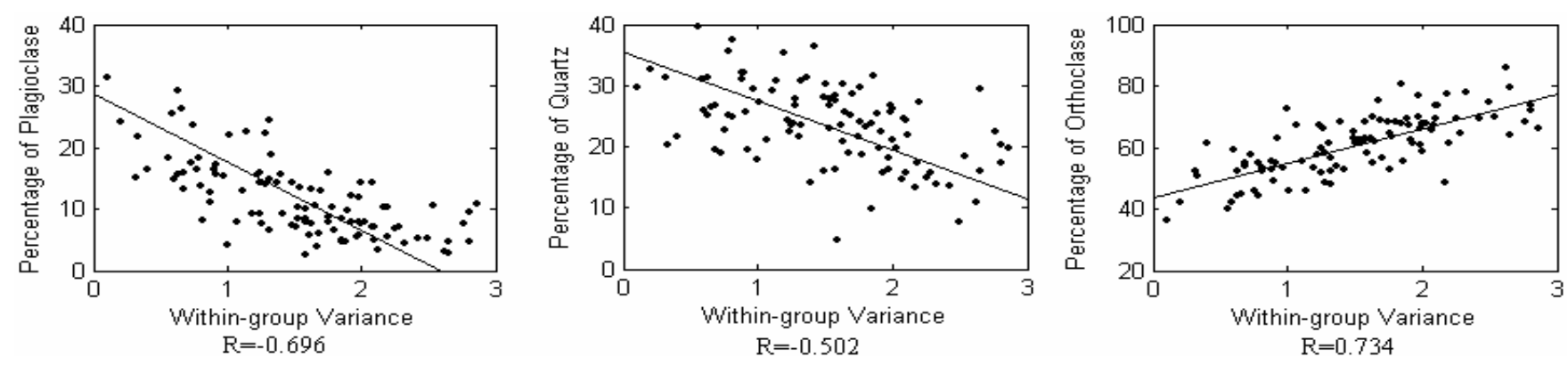

Fig. 6. Plots showing the relationship between the within-group variance calculated from the scaling analysis and the percentages of plagioclases, quartz and orthoclase, respectively. $R$ is correlation coefficient.

Table 1. Data obtained for element " 2 " from sample 3 for void analysis.

\begin{tabular}{lllllllllll}
\hline Length $(\mathrm{k}>1)$ & 2 & 3 & 4 & 5 & 6 & 7 & 8 & 9 & 10 & 18 \\
Frequency $[\mathrm{N}(v=\mathrm{k})]$ & 213 & 67 & 44 & 17 & 7 & 1 & 6 & 1 & 1 & 1 \\
Accumulative & 358 & 145 & 78 & 34 & 17 & 10 & 9 & 3 & 2 & 1 \\
frequency $[\mathrm{N}(v \geq \mathrm{k})]$ & & & & & & & & & & \\
\hline
\end{tabular}

Table 2. Data obtained for element "2" from sample 3 for cluster analysis.

\begin{tabular}{lllll}
\hline Length $(\mathrm{k})$ & 1 & 2 & 3 & 4 \\
Frequency [N(c=k)] & 296 & 51 & 11 & 3 \\
Accumulative frequency & 361 & 65 & 14 & 3 \\
{$[\mathrm{~N}(\mathrm{c} \geq \mathrm{k})]$} & & & & \\
\hline
\end{tabular}

sample 3. From the plots we can see that the relationships between $\log \left[N\left(v\left(a_{i}\right)=k\right)\right]$ and $\log (k), \log \left[N\left(c\left(a_{i}\right)=k\right)\right]$ and $\log (k)$ are linear. The data for voids in Fig. 3b were fitted by a straight-line using least squares which gives the estimated slope $=2.45$, correlation coefficient $R=0.85$ and $\mathrm{t}$ statistics as $t=4.66$, respectively. The results of correlation coefficient and t-statistics indicate that the linear relationship between $\log \left[N\left(v\left(a_{i}\right)=k\right)\right]$ and $\log (k)$ is are statistically significant which implies that the power-law relationship holds true between $N\left(v\left(a_{i}\right)=k\right)$ and $k$. This example validates that model (2) does hold true for the element "2" in sample 3. Similarly we have treated the data for other elements " 1 " and " 3 " from sample 3 and the results are plotted in Figs. 3a and $\mathrm{c}$ for voids and Figs. $3 \mathrm{~d}$ and $\mathrm{f}$ for clusters, respectively. In the same way, the accumulative cases can be investigated as Fig. 3 shows.

Similar analysis was applied to all other samples and the results for CSI and VSI analyses are shown in Table 3. Among the 104 samples, except one mineral of five samples $(98,135,138,139$ and 142), all other samples from the study area gave consistent results showing that the power-law rela- tionships (1) and (2) are generally hold true for the clusters and voids of plagioclase, quartz and orthoclase. We may conclude that granite sequences collected from the study area show cluster scaling invariance and void scaling invariance properties which can be characterized by models (1) and (2) defined in this paper. Similar results were found to hold true for the accumulative scaling invariance for clusters and voids in all the samples (Fig. 4).

3.3 Variance of scale invariance index of three minerals and its significance for characterizing granite crystallization

Since the scale invariance properties of mineral clusters and voids quantified using the exponents $\alpha$ and $\beta$, respectively, characterize the power-law distributions of the frequency of clusters and voids, the values of these exponents $\alpha$ and $\beta$ reflect the degrees of complexity of the distribution of minerals; for example, a larger $\alpha$ value of a mineral in a sequence corresponds more rapid decrease of number of clusters with cluster size increasing, which implies relatively more small clusters than large clusters of mineral grains. The smaller value of $\alpha$ may, on the other hand, indicate less randomness and more uniform of distribution of mineral grains. Therefore, if a standard deviation calculated from $\alpha$ values of the three minerals, it may reflect the overall heterogeneity of the mineral grains. If the standard deviation is large it means that some minerals show high degree of randomness whereas others show less randomness in distribution of grains indicating a general constraint on the crystallization of granites. The results of within-group standard deviation were calculated for all samples and the results are plotted in Fig. 5 based on 
Table 3. Results obtained for clusters and voids of elements from Ideal Granite sequences used by Vistelius et al. (1983).

\begin{tabular}{|c|c|c|c|c|c|c|c|c|c|c|c|c|c|c|c|c|c|c|c|}
\hline \multirow[b]{4}{*}{ No } & \multirow{4}{*}{$\begin{array}{l}\text { Sample } \\
\text { Code }\end{array}$} & \multicolumn{9}{|c|}{ Void analysis } & \multicolumn{9}{|c|}{ Cluster analysis } \\
\hline & & \multicolumn{18}{|c|}{ Minerals } \\
\hline & & & 1 & & & 2 & & & 3 & & & 1 & & & 2 & & & 3 & \\
\hline & & $\alpha$ & $R$ & $t$ & $\alpha$ & $R$ & $t$ & $\alpha$ & $R$ & $t$ & $\alpha$ & $R$ & $t$ & $\alpha$ & $R$ & $t$ & $\alpha$ & $R$ & $t$ \\
\hline 1 & COG-2 & 5.49 & 1.00 & 559. & 2.35 & 0.97 & 11.6 & 0.97 & 0.76 & 5.87 & 2.77 & 0.97 & 9.43 & 4.55 & 1.00 & 11.3 & & & \\
\hline 2 & COG-3 & 4.43 & 0.94 & 6.23 & 2.54 & 0.97 & 11.4 & 0.88 & 0.75 & 5.50 & 2.80 & 0.88 & 3.72 & 3.08 & 0.97 & 3.99 & 5.77 & 1 & $\mathrm{NaN}$ \\
\hline 3 & COG-4 & 4.72 & 0.99 & 17.3 & 2.46 & 0.86 & 4.67 & 0.94 & 0.67 & 4.11 & 3.32 & 0.93 & 4.28 & 3.27 & 0.98 & 7.39 & 5.78 & 1 & $\mathrm{NaN}$ \\
\hline 4 & COG-5 & 4.83 & 0.97 & 8.14 & 2.39 & 0.97 & 9.90 & 0.70 & 0.69 & 4.98 & 2.98 & 0.93 & 5.25 & 3.83 & 0.96 & 6.06 & 5.42 & 1 & $\mathrm{NaN}$ \\
\hline 5 & COG-6 & 3.10 & 0.98 & 13.4 & 2.12 & 0.91 & 5.68 & 1.85 & 0.94 & 10.9 & 4.04 & 0.97 & 5.86 & 3.16 & 0.92 & 4.03 & 4.68 & 0.96 & 3.63 \\
\hline 6 & COG-7 & 3.18 & 0.92 & 6.48 & 2.56 & 0.97 & 9.83 & 2.01 & 0.89 & 7.19 & 3.31 & 0.98 & 6.48 & 3.42 & 0.95 & 4.36 & 3.72 & 1 & $\mathrm{NaN}$ \\
\hline 7 & COG-8 & 3.94 & 0.97 & 9.49 & 1.73 & 0.88 & 6.67 & 1.73 & 0.89 & 7.88 & 2.59 & 0.97 & 9.12 & 4.06 & 0.97 & 3.69 & 3.50 & 0.95 & 4.33 \\
\hline 8 & COG-10 & 4.60 & 0.99 & 12.6 & 2.38 & 0.93 & 7.55 & 0.75 & 0.74 & 5.54 & 2.55 & 0.91 & 4.92 & 3.68 & 0.99 & 8.41 & 6.39 & 1 & $\mathrm{NaN}$ \\
\hline 9 & COG-11 & 4.16 & 0.94 & 5.30 & 2.35 & 0.95 & 9.69 & 1.59 & 0.87 & 7.73 & 2.83 & 0.93 & 4.33 & 3.20 & 0.94 & 4.92 & 4.86 & 1 & $\mathrm{NaN}$ \\
\hline 10 & COG-12 & 3.13 & 0.85 & 4.34 & 2.54 & 0.92 & 6.67 & 1.88 & 0.81 & 5.26 & 3.03 & 0.96 & 6.04 & 3.18 & 0.98 & 7.33 & 3.25 & 1.00 & 23.1 \\
\hline 11 & COG-13 & 3.00 & 0.88 & 5.24 & 2.66 & 0.97 & 12.3 & 1.51 & 0.85 & 6.73 & 3.34 & 0.97 & 5.79 & 3.51 & 0.93 & 4.56 & 3.66 & 1.00 & 13.2 \\
\hline 12 & COG-14 & 3.31 & 0.95 & 6.64 & 2.35 & 0.96 & 8.21 & 1.83 & 0.85 & 6.09 & 2.99 & 0.96 & 4.67 & 2.98 & 0.96 & 4.93 & 3.96 & 1 & $\mathrm{NaN}$ \\
\hline 13 & COG-15 & 3.74 & 0.98 & 8.45 & 2.56 & 0.96 & 9.04 & 1.09 & 0.73 & 4.83 & 2.63 & 0.98 & 10.1 & 3.77 & 0.90 & 2.96 & 5.12 & 1 & $\mathrm{NaN}$ \\
\hline 14 & COG-16 & 4.57 & 0.99 & 11.2 & 2.64 & 0.97 & 12.3 & 1.52 & 0.86 & 7.62 & 3.29 & 0.92 & 3.95 & 3.66 & 0.98 & 9.17 & 7.31 & 1 & $\mathrm{NaN}$ \\
\hline 15 & COG-17 & 3.85 & 0.96 & 7.00 & 2.03 & 0.96 & 11.3 & 1.45 & 0.85 & 7.10 & 2.66 & 0.96 & 8.60 & 4.05 & 0.96 & 12.9 & 4.91 & 1 & $\mathrm{NaN}$ \\
\hline 16 & COG-18 & 3.99 & 0.98 & 9.10 & 2.80 & 0.98 & 12.9 & 1.19 & 0.71 & 4.92 & 3.29 & 0.95 & 4.37 & 3.41 & 0.94 & 7.75 & 4.53 & 0.98 & 4.46 \\
\hline 17 & COG-19 & 4.03 & 0.93 & 5.87 & 2.45 & 0.97 & 12.2 & 1.40 & 0.85 & 7.82 & 3.04 & 0.94 & 5.70 & 2.86 & 0.96 & 6.54 & 4.30 & 1 & $\mathrm{NaN}$ \\
\hline 18 & COG-20 & 3.57 & 0.95 & 8.05 & 2.51 & 0.98 & 13.4 & 1.04 & 0.78 & 6.43 & 3.26 & 0.93 & 4.29 & 2.78 & 0.92 & 5.29 & 4.14 & 1 & $\mathrm{NaN}$ \\
\hline 19 & COG-D-1 & 2.57 & 0.64 & 1.71 & 2.44 & 0.95 & 9.84 & 0.77 & 0.61 & 4.18 & 2.61 & 0.86 & 3.72 & 4.59 & 1.00 & 21.7 & & & \\
\hline 20 & COG-D-2 & 2.30 & 0.90 & 6.35 & 2.50 & 0.90 & 5.69 & 2.45 & 0.95 & 10.6 & 4.14 & 0.98 & 8.05 & 2.98 & 0.93 & 5.03 & 3.28 & 0.97 & 6.05 \\
\hline 21 & COG-D-3 & 4.35 & 0.98 & 7.92 & 2.11 & 0.89 & 5.87 & 1.29 & 0.80 & 5.51 & 2.83 & 0.94 & 5.78 & 4.76 & 0.88 & 1.81 & 5.23 & 1 & $\mathrm{NaN}$ \\
\hline 22 & COG-D-4 & 5.03 & 0.99 & 12.3 & 2.17 & 0.98 & 16.2 & 0.56 & 0.47 & 2.75 & 1.94 & 0.97 & 9.19 & 4.06 & 0.99 & 13.1 & 5.34 & 1 & $\mathrm{NaN}$ \\
\hline 23 & COG-D-5 & 6.27 & 0.99 & 8.22 & 2.36 & 0.97 & 11.2 & 0.82 & 0.63 & 4.10 & 2.39 & 0.96 & 7.43 & 3.91 & 1.00 & 23.6 & & & \\
\hline 24 & COG-D-6 & 4.13 & 0.97 & 7.12 & 2.53 & 0.97 & 9.12 & 1.33 & 0.73 & 4.47 & 3.16 & 0.93 & 4.95 & 3.85 & 0.94 & 3.99 & 5.7 & 1 & $\mathrm{NaN}$ \\
\hline 25 & COG-D-7 & 3.89 & 0.95 & 7.23 & 2.50 & 0.97 & 13.1 & 1.79 & 0.87 & 6.42 & 3.08 & 0.99 & 8.77 & 3.54 & 1.00 & 26.9 & 3.83 & 0.99 & 7.13 \\
\hline 26 & COG-D-8 & 2.72 & 0.96 & 8.48 & 2.39 & 0.92 & 5.72 & 1.41 & 0.81 & 5.80 & 2.96 & 0.94 & 4.64 & 2.52 & 0.99 & 11.4 & 4.44 & 0.97 & 4.20 \\
\hline 27 & COG-D-9 & 3.98 & 0.95 & 7.39 & 2.65 & 0.98 & 13.4 & 1.00 & 0.75 & 5.59 & 2.84 & 0.91 & 4.36 & 2.92 & 0.95 & 5.40 & 4.86 & 1 & $\mathrm{NaN}$ \\
\hline 28 & COG-D-10 & 2.41 & 0.95 & 10.2 & 2.51 & 0.96 & 9.39 & 2.79 & 0.95 & 9.65 & 5.02 & 0.97 & 4.01 & 2.97 & 0.94 & 5.55 & 3.71 & 0.92 & 3.24 \\
\hline 29 & COG-D-11 & 3.24 & 0.98 & 12.8 & 2.53 & 0.98 & 13.5 & 1.67 & 0.86 & 7.36 & 3.39 & 0.97 & 6.97 & 3.13 & 0.96 & 5.67 & 3.64 & 1 & $\mathrm{NaN}$ \\
\hline 30 & COG-D-12 & 2.70 & 0.97 & 11.4 & 2.13 & 0.92 & 6.22 & 2.15 & 0.86 & 5.30 & 3.52 & 0.99 & 10.1 & 2.85 & 0.96 & 7.49 & 3.49 & 0.92 & 3.39 \\
\hline 31 & COG-D-13 & 3.57 & 0.97 & 7.87 & 2.61 & 0.95 & 8.76 & 2.13 & 0.92 & 8.52 & 3.43 & 1.00 & 14.9 & 2.98 & 1.00 & 17.3 & 4.25 & 0.99 & 7.48 \\
\hline 32 & COG-D-14 & 4.64 & 1.00 & 19.0 & 2.65 & 0.96 & 10.3 & 0.71 & 0.61 & 3.98 & 2.54 & 0.97 & 7.86 & 3.03 & 0.99 & 11.3 & 5.52 & 1 & $\mathrm{NaN}$ \\
\hline 33 & COG-D-15 & 2.93 & 0.95 & 8.95 & 2.50 & 0.97 & 11.1 & 2.13 & 0.88 & 6.32 & 3.26 & 0.96 & 6.32 & 3.15 & 0.99 & 16.8 & 3.35 & 0.97 & 4.38 \\
\hline 34 & COG-D-16 & 4.20 & 0.98 & 9.26 & 2.60 & 0.97 & 7.66 & 0.95 & 0.81 & 6.97 & 3.06 & 0.95 & 6.19 & 3.27 & 0.99 & 10.7 & 6.74 & 1 & $\mathrm{NaN}$ \\
\hline 35 & COG-D-17 & 3.04 & 0.94 & 6.60 & 2.78 & 0.95 & 7.75 & 1.97 & 0.88 & 6.09 & 3.52 & 0.97 & 5.53 & 3.70 & 0.89 & 2.69 & 3.78 & 0.99 & 9.93 \\
\hline 36 & COG-D-18 & 5.26 & 0.92 & 3.43 & 2.40 & 0.95 & 7.81 & 1.62 & 0.88 & 8.23 & 3.19 & 0.97 & 7.49 & 3.61 & 0.97 & 4.24 & 4.90 & 0.94 & 2.73 \\
\hline 37 & COG-D-19 & 4.08 & 0.98 & 9.85 & 2.45 & 0.97 & 11.6 & 1.65 & 0.90 & 8.53 & 2.95 & 0.99 & 8.50 & 3.41 & 0.98 & 4.60 & 3.43 & 1.00 & 22.4 \\
\hline 38 & COG-D-20 & 4.35 & 0.97 & 7.19 & 2.78 & 0.93 & 6.67 & 0.75 & 0.59 & 3.39 & 2.56 & 0.89 & 3.47 & 4.21 & 0.98 & 6.65 & 5.67 & 1 & $\mathrm{NaN}$ \\
\hline 39 & COG-D-21 & 5.13 & 0.97 & 6.83 & 2.36 & 0.91 & 6.43 & 1.26 & 0.80 & 6.10 & 2.80 & 0.94 & 4.60 & 3.29 & 0.98 & 5.54 & 7.13 & 1 & $\mathrm{NaN}$ \\
\hline 40 & COG-D-22 & 4.46 & 0.95 & 7.11 & 3.03 & 0.96 & 8.21 & 0.78 & 0.61 & 4.02 & 3.70 & 0.95 & 4.39 & 2.86 & 0.94 & 4.97 & 5.00 & 1 & $\mathrm{NaN}$ \\
\hline 41 & COG-D-23 & 5.67 & 0.99 & 9.79 & 2.56 & 0.99 & 16.8 & 0.46 & 0.43 & 2.49 & 2.67 & 0.92 & 5.33 & 4.11 & 0.96 & 3.51 & & & \\
\hline 42 & COG-D-24 & 5.37 & 1.00 & 15.4 & 2.02 & 0.94 & 8.70 & 0.90 & 0.80 & 6.66 & 2.58 & 0.87 & 4.64 & 4.17 & 0.99 & 6.23 & & & \\
\hline 43 & COG-D-25 & 3.47 & 0.93 & 6.35 & 2.61 & 0.96 & 9.18 & 1.65 & 0.92 & 9.57 & 2.79 & 0.96 & 4.86 & 3.70 & 0.95 & 5.51 & 3.74 & 1.00 & 17.7 \\
\hline 44 & COG-D-26 & 3.93 & 0.93 & 4.25 & 2.93 & 0.96 & 9.29 & 0.63 & 0.59 & 3.62 & 3.09 & 0.90 & 4.05 & 3.01 & 0.89 & 3.40 & & & \\
\hline 45 & COG-D-27 & 3.56 & 0.95 & 6.65 & 2.58 & 0.96 & 9.48 & 1.34 & 0.88 & 8.99 & 3.05 & 0.96 & 7.41 & 3.72 & 0.95 & 5.03 & 4.51 & 0.99 & 7.45 \\
\hline 46 & COG-D-28 & 3.88 & 0.97 & 9.98 & 3.04 & 0.96 & 8.14 & 0.82 & 0.67 & 4.66 & 3.06 & 0.86 & 2.90 & 2.67 & 1.00 & 19.3 & 4.98 & 1 & $\mathrm{NaN}$ \\
\hline 47 & COG-D-29 & 3.43 & 0.95 & 7.34 & 2.62 & 0.99 & 16.2 & 0.98 & 0.85 & 8.12 & 2.78 & 0.93 & 5.74 & 2.81 & 0.97 & 6.11 & 5.85 & 1 & $\mathrm{NaN}$ \\
\hline 48 & COG-D-30 & 3.98 & 0.95 & 5.97 & 2.44 & 0.94 & 8.11 & 0.72 & 0.72 & 5.39 & 2.61 & 0.88 & 4.04 & 2.95 & 0.96 & 5.84 & 4.72 & 1 & $\mathrm{NaN}$ \\
\hline 72 & COG-D-78 & 4.33 & 0.97 & 8.44 & 2.41 & 0.97 & 10.6 & 1.00 & 0.76 & 5.51 & 3.08 & 0.95 & 6.28 & 2.89 & 0.96 & 7.10 & 6.88 & 1 & $\mathrm{NaN}$ \\
\hline 73 & COG-D-79 & 3.39 & 0.94 & 6.06 & 2.82 & 0.94 & 7.04 & 1.03 & 0.71 & 4.68 & 2.98 & 0.97 & 8.68 & 2.67 & 0.91 & 3.88 & 4.91 & 1 & $\mathrm{NaN}$ \\
\hline 74 & COG-D-80 & 4.87 & 0.95 & 5.38 & 2.13 & 0.98 & 14.4 & 0.97 & 0.73 & 5.50 & 2.68 & 0.94 & 5.52 & 2.88 & 0.97 & 6.11 & 5.06 & 1 & $\mathrm{NaN}$ \\
\hline 75 & COG-D-81 & 3.97 & 0.98 & 10.4 & 2.44 & 0.96 & 9.45 & 1.43 & 0.87 & 7.58 & 3.57 & 0.92 & 3.95 & 2.98 & 0.97 & 7.11 & 4.67 & 1.00 & 33.1 \\
\hline 76 & COG-D-82 & 4.04 & 0.95 & 6.36 & 2.61 & 0.91 & 5.82 & 0.55 & 0.59 & 4.26 & 2.77 & 0.91 & 4.41 & 2.91 & 0.96 & 7.04 & 6.08 & 1 & $\mathrm{NaN}$ \\
\hline 77 & COG-D-83 & 3.75 & 1.00 & 213. & 2.88 & 0.98 & 12.6 & 0.37 & 0.37 & 2.08 & 2.81 & 0.95 & 5.45 & 2.68 & 0.99 & 9.02 & & & \\
\hline 86 & COG-F-1 & 2.75 & 0.94 & 7.34 & 2.11 & 0.97 & 11.5 & 2.33 & 0.92 & 8.33 & 2.74 & 0.94 & 4.06 & 2.65 & 0.95 & 6.00 & 4.88 & 0.98 & 5.40 \\
\hline 87 & COG-F-2 & 3.54 & 0.96 & 8.12 & 2.32 & 0.97 & 11.7 & 1.83 & 0.84 & 6.05 & 2.96 & 0.97 & 5.25 & 3.22 & 0.95 & 5.31 & 4.82 & 1.00 & 14.5 \\
\hline 88 & COG-F-3 & 4.79 & 0.96 & 6.84 & 2.52 & 0.99 & 16.8 & 0.60 & 0.55 & 3.47 & 1.97 & 1.00 & 18.8 & 2.72 & 0.93 & 3.63 & & & \\
\hline 89 & COG-F-4 & 3.07 & 0.89 & 5.62 & 2.25 & 0.95 & 9.86 & 1.71 & 0.85 & 6.09 & 2.96 & 0.95 & 5.20 & 3.15 & 0.95 & 6.08 & 3.66 & 0.97 & 3.71 \\
\hline 90 & COG-F-5 & 3.37 & 0.97 & 9.45 & 2.09 & 0.93 & 7.03 & 1.63 & 0.85 & 5.95 & 3.20 & 0.98 & 7.28 & 2.87 & 0.93 & 5.52 & 3.73 & 1 & $\mathrm{NaN}$ \\
\hline 91 & COG-F-6 & 3.79 & 0.97 & 8.33 & 2.55 & 0.92 & 5.95 & 1.18 & 0.85 & 6.58 & 2.57 & 0.91 & 3.74 & 3.17 & 0.99 & 7.78 & 4.79 & 1 & $\mathrm{NaN}$ \\
\hline 92 & COG-F-8 & 5.02 & 0.92 & 3.28 & 2.52 & 0.95 & 9.38 & 0.81 & 0.74 & 5.67 & 2.89 & 0.93 & 6.48 & 4.10 & 0.90 & 2.88 & & & \\
\hline
\end{tabular}


Table 3. Continued.

\begin{tabular}{|c|c|c|c|c|c|c|c|c|c|c|c|c|c|c|c|c|c|c|c|}
\hline \multirow[b]{4}{*}{ No } & \multirow{4}{*}{$\begin{array}{l}\text { Sample } \\
\text { Code }\end{array}$} & \multicolumn{9}{|c|}{ Void analysis } & \multicolumn{9}{|c|}{ Cluster analysis } \\
\hline & & \multicolumn{18}{|c|}{ Minerals } \\
\hline & & \multirow{2}{*}{\multicolumn{2}{|c|}{$\begin{array}{l}1 \\
R\end{array}$}} & \multirow[b]{2}{*}{$t$} & \multirow[b]{2}{*}{$\alpha$} & \multicolumn{2}{|l|}{2} & \multicolumn{3}{|c|}{3} & \multicolumn{3}{|c|}{1} & \multicolumn{3}{|c|}{2} & \multicolumn{3}{|c|}{3} \\
\hline & & & & & & $R$ & $t$ & $\alpha$ & $R$ & $t$ & $\alpha$ & $R$ & $t$ & $\alpha$ & $R$ & $t$ & $\alpha$ & $R$ & $t$ \\
\hline 93 & COG-F-9 & 4.27 & 0.97 & 7.83 & 1.84 & 0.91 & 7.03 & 1.27 & 0.81 & 6.49 & 2.54 & 0.90 & 5.53 & 3.52 & 0.97 & 3.73 & 4.50 & 0.99 & 7.48 \\
\hline 94 & COG-F-10 & 3.19 & 0.99 & 14.4 & 2.85 & 0.97 & 9.15 & 1.52 & 0.87 & 6.97 & 3.06 & 0.97 & 7.17 & 3.06 & 0.99 & 8.80 & 4.20 & 0.99 & 9.68 \\
\hline 95 & COG-F-11 & 4.10 & 0.91 & 4.30 & 3.02 & 0.92 & 5.95 & 0.91 & 0.65 & 4.37 & 3.05 & 0.85 & 2.78 & 3.19 & 0.96 & 4.91 & 4.29 & 1 & $\mathrm{NaN}$ \\
\hline 96 & COG-F-12 & 5.16 & 0.98 & 8.84 & 2.05 & 0.93 & 7.74 & 1.16 & 0.74 & 5.21 & 2.53 & 0.94 & 7.34 & 3.46 & 1.00 & 12.7 & 4.98 & 1 & $\mathrm{NaN}$ \\
\hline 97 & COG-F-13 & 6.27 & 0.98 & 6.69 & 2.41 & 0.96 & 9.62 & 0.80 & 0.74 & 5.62 & 2.39 & 0.94 & 5.50 & 4.30 & 0.94 & 2.71 & 5.48 & 1 & $\mathrm{NaN}$ \\
\hline 98 & COG-F-27 & 4.95 & 0.98 & 9.20 & 3.30 & 0.97 & 9.13 & 0.17 & 0.22 & 1.18 & 2.80 & 0.95 & 6.37 & 3.88 & 0.96 & 5.69 & 5.25 & 1 & $\mathrm{NaN}$ \\
\hline 99 & COG-F-16 & 3.15 & 0.97 & 8.48 & 2.44 & 0.97 & 12.4 & 1.89 & 0.93 & 9.78 & 3.49 & 0.96 & 6.26 & 2.83 & 0.97 & 7.96 & 4.15 & 1.00 & 8.2 \\
\hline 100 & COG-F-17 & 4.84 & 0.94 & 4.64 & 2.76 & 0.97 & 10.8 & 1.07 & 0.68 & 4.39 & 3.20 & 0.88 & 3.13 & 2.98 & 1.00 & 38.7 & 5.94 & 1 & $\mathrm{aN}$ \\
\hline 101 & COG-F-18 & 3.78 & 0.95 & 7.09 & 2.46 & 0.96 & 9.53 & 1.41 & 0.86 & 7.95 & 3.10 & 0.94 & 5.47 & 3.77 & 0.93 & 3.51 & 4.57 & 1.00 & 5.2 \\
\hline 102 & COG-F-19 & 3.83 & 0.96 & 8.37 & 2.61 & 0.96 & 9.86 & 1.91 & 0.89 & 7.92 & 3.32 & 0.96 & 4.82 & 3.37 & 0.93 & 3.62 & 4.09 & 0.99 & 7.07 \\
\hline 103 & COG-F-20 & 3.41 & 0.96 & 6.12 & 2.67 & 0.93 & 6.64 & 0.96 & 0.72 & 5.16 & 3.25 & 0.93 & 5.59 & 3.34 & 0.94 & 4.02 & 4.16 & 1 & $\mathrm{NaN}$ \\
\hline 104 & COG-F-21 & 6.12 & 0.97 & 5.39 & 2.68 & 0.96 & 9.89 & 0.45 & 0.38 & 2.33 & 2.72 & 0.90 & 4.69 & 4.44 & 0.95 & 3.11 & & & \\
\hline 105 & COG-F-22 & 3.52 & 0.95 & 8.23 & 2.65 & 0.96 & 9.18 & 1.88 & 0.85 & 6.90 & 3.80 & 0.93 & 4.34 & 2.85 & 0.96 & 6.90 & 4.36 & 1 & $\mathrm{NaN}$ \\
\hline 106 & COG-F-24 & 4.42 & 0.98 & 7.82 & 2.45 & 0.97 & 10.5 & 1.29 & 0.80 & 6.41 & 3.16 & 0.88 & 3.16 & 3.62 & 0.99 & 9.98 & 4.77 & 1 & $\mathrm{NaN}$ \\
\hline 107 & COG-F-25 & 4.32 & 0.95 & 6.73 & 2.88 & 0.97 & 9.56 & 1.27 & 0.80 & 5.62 & 3.45 & 0.95 & 6.00 & 3.34 & 0.95 & 5.22 & 4.39 & 1 & $\mathrm{NaN}$ \\
\hline 108 & COG-F-26 & 3.96 & 0.86 & 3.83 & 2.68 & 0.95 & 7.76 & 0.96 & 0.79 & 6.49 & 3.14 & 0.95 & 6.11 & 2.93 & 0.97 & 7.92 & 4.36 & 1 & $\mathrm{NaN}$ \\
\hline 109 & COG-F-28 & 5.86 & 0.96 & 5.61 & 3.46 & 0.98 & 13.2 & 0.57 & 0.53 & 3.36 & 3.40 & 0.97 & 7.58 & 3.60 & 0.97 & 3.84 & & & \\
\hline 110 & COG-F-29 & 3.68 & 0.98 & 9.15 & 2.41 & 0.91 & 5.69 & 1.68 & 0.90 & 8.52 & 3.54 & 0.97 & 6.07 & 2.84 & 0.96 & 7.06 & 4.58 & 1 & $\mathrm{NaN}$ \\
\hline 111 & COG-F-30 & 4.92 & 0.95 & 5.50 & 1.90 & 0.93 & 8.44 & 0.71 & 0.67 & 4.65 & 2.02 & 0.89 & 5.19 & 3.33 & 0.97 & 6.21 & 6.44 & 1 & $\mathrm{NaN}$ \\
\hline 112 & COG-F-31 & 4.40 & 0.93 & 5.83 & 3.12 & 0.97 & 8.91 & 1.03 & 0.73 & 5.21 & 3.24 & 0.95 & 4.15 & 3.27 & 0.89 & 2.80 & 4.82 & 1 & $\mathrm{NaN}$ \\
\hline 113 & COG-F-32 & 4.74 & 0.98 & 9.77 & 2.46 & 0.95 & 9.71 & 1.08 & 0.83 & 7.74 & 2.73 & 0.92 & 5.25 & 3.53 & 0.98 & 9.64 & & & \\
\hline 114 & COG-F-33 & 3.36 & 0.99 & 16.2 & 1.53 & 0.88 & 7.05 & 2.32 & 0.95 & 11.1 & 3.08 & 0.94 & 5.54 & 2.90 & 0.88 & 2.67 & 3.43 & 0.98 & 8.77 \\
\hline 115 & COG-F-34 & 3.03 & 0.99 & 16.1 & 1.83 & 0.95 & 9.69 & 2.53 & 0.95 & 8.28 & 3.12 & 1 & $\mathrm{NaN}$ & 3.58 & 1.00 & 12.8 & 3.02 & 0.96 & 4.64 \\
\hline 116 & COG-F-35 & 3.02 & 0.92 & 6.43 & 0.87 & 0.81 & 6.25 & 3.42 & 0.96 & 8.76 & 4.27 & 0.99 & 8.79 & 2.70 & 0.97 & 6.45 & 2.73 & 0.89 & 4.45 \\
\hline 117 & COG-F-36 & 2.89 & 0.96 & 8.35 & 1.29 & 0.89 & 7.63 & 2.35 & 0.83 & 4.78 & 3.64 & 0.98 & 7.53 & 2.81 & 0.95 & 6.06 & 3.02 & 0.92 & 4.02 \\
\hline 118 & COG-1 & 4.19 & 0.97 & 7.55 & 1.55 & 0.93 & 9.60 & 1.67 & 0.94 & 10.7 & 2.49 & 0.95 & 6.84 & 3.65 & 0.99 & 9.41 & 4.72 & 0.98 & 5.29 \\
\hline 119 & COG-D-37 & 5.16 & 0.89 & 3.30 & 2.23 & 0.91 & 7.16 & 1.3 & 0.85 & 7.51 & 2.84 & 0.94 & 6.88 & 2.80 & 0.99 & 6.35 & 4.14 & 1 & $\mathrm{NaN}$ \\
\hline 128 & COG-D-46 & 4.92 & 0.96 & 6.17 & 2.20 & 0.97 & 11.7 & 0.96 & 0.79 & 6.51 & 2.89 & 0.87 & 4.04 & 3.54 & 0.97 & 5.39 & 4.38 & 0.95 & 2.92 \\
\hline 129 & COG-D-47 & 4.27 & 0.96 & 6.23 & 2.39 & 0.98 & 12.9 & 1.25 & 0.85 & 7.45 & 2.44 & 0.97 & 6.14 & 3.32 & 0.95 & 5.50 & 6.02 & 1 & $\mathrm{NaN}$ \\
\hline 130 & COG-D-55 & 4.07 & 0.95 & 5.58 & 2.68 & 0.95 & 8.21 & 1.24 & 0.77 & 5.51 & 3.15 & 0.94 & 5.51 & 3.35 & 0.95 & 5.27 & 4.99 & 1 & $\mathrm{NaN}$ \\
\hline 133 & COG-D-68 & 5.22 & 0.99 & 10.3 & 2.84 & 0.94 & 7.86 & 0.66 & 0.57 & 3.56 & 2.92 & 0.91 & 4.52 & 3.70 & 0.96 & 4.56 & 5.32 & 1 & $\mathrm{NaN}$ \\
\hline 134 & COG-D-69 & 5.00 & 0.98 & 7.65 & 2.87 & 0.96 & 8.87 & 0.61 & 0.55 & 3.59 & 3.06 & 0.91 & 4.92 & 3.46 & 0.98 & 6.28 & 6.27 & 1 & $\mathrm{NaN}$ \\
\hline 135 & COG-D-70 & 5.29 & 0.97 & 7.32 & 3.00 & 0.94 & 7.27 & 0.01 & 0.00 & 0.01 & 2.85 & 0.86 & 3.37 & 3.58 & 0.98 & 8.32 & & & \\
\hline 136 & COG-D-71 & 5.04 & 0.97 & 7.73 & 2.49 & 0.94 & 8.03 & 0.69 & 0.68 & 4.29 & 2.20 & 0.92 & 5.42 & 3.74 & 0.95 & 4.12 & 4.27 & 1 & $\mathrm{NaN}$ \\
\hline 137 & COG-D-72 & 5.53 & 0.97 & 7.14 & 2.29 & 0.91 & 6.03 & 0.61 & 0.61 & 4.29 & 2.35 & 0.86 & 3.74 & 3.74 & 0.89 & 2.78 & & & \\
\hline 138 & COG-D-73 & 4.12 & 0.97 & 6.90 & 2.67 & 0.99 & 15.4 & 0.21 & 0.11 & 0.61 & 2.78 & 0.95 & 5.91 & 2.98 & 0.97 & 6.51 & & & \\
\hline 139 & COG-D-74 & 5.74 & 0.90 & 2.84 & 2.90 & 0.97 & 10.1 & 0.22 & 0.29 & 1.50 & 2.74 & 0.90 & 4.98 & 2.41 & 0.94 & 2.87 & & & \\
\hline 140 & COG-D-75 & 2.83 & 0.94 & 8.35 & 3.46 & 0.96 & 7.91 & 1.25 & 0.85 & 6.22 & 3.74 & 0.98 & 7.84 & 3.23 & 0.91 & 4.39 & 5.00 & 1 & $\mathrm{NaN}$ \\
\hline 141 & COG-D-76 & 4.96 & 0.97 & 8.23 & 2.51 & 0.95 & 7.70 & 0.81 & 0.79 & 6.36 & 2.63 & 0.89 & 3.93 & 3.95 & 0.96 & 4.84 & 5.48 & 1 & $\mathrm{NaN}$ \\
\hline 142 & COG-D-77 & 5.19 & 0.92 & 3.96 & 3.24 & 0.93 & 6.22 & 0.15 & 0.05 & 0.26 & 2.96 & 0.90 & 4.16 & 3.45 & 0.97 & 5.93 & & & \\
\hline 143 & COG-D-86 & 4.14 & 0.98 & 8.41 & 3.29 & 0.97 & 10.6 & 0.76 & 0.62 & 3.70 & 3.48 & 0.96 & 5.94 & 2.85 & 0.98 & 6.61 & & & \\
\hline 144 & COG-D-92 & 5.04 & 0.97 & 7.10 & 3.14 & 0.69 & 8.56 & 1.04 & 0.74 & 5.15 & 3.58 & 0.97 & 5.54 & 3.75 & 0.97 & 5.72 & 5.24 & 1 & $\mathrm{NaN}$ \\
\hline
\end{tabular}

Note: The cells with NaN or cells as blanks represent the situations that only one or two lengths of clusters of minerals for which it can not fit with linear function.

the samples in the rectangular area in Fig. 1. The levels of within-group standard deviation are represented proportional to the size of the dots. A visual comparison of within-group standard deviation of $\alpha$-value (represented as dot size) with the percentages of plagioclase (represented as color patterns) clearly demonstrates that the standard deviation is negatively correlated to the percentage of plagioclase. Similar results were obtained by plotting the standard deviation of $\alpha$-value against the percentages of plagioclase as a scatter plot shown in Fig. 6a. Figure 6a shows a clear trend with a correlation coefficient $R=-0.696$ implying a statistical significant correlation between the standard deviation and the percentage of plagioclase. Similarly, the results calculated for orthoclase and quartz show that the standard deviation of $\alpha$-value is negatively correlated with percentage of quartz and positively correlated with the percentage of orthoclase. This discovery is interest since it may represent overall influence of viscosity of the magma on randomness of crystallization. Comparing the results obtained with standard deviation of the $\alpha$-value with those with first or second-order Markov model, one can 
Table 4. Summary table providing statistics obtained from all samples from the Meech Lake aplite.

\begin{tabular}{|c|c|c|c|c|c|c|c|c|c|c|c|c|}
\hline & \multirow{2}{*}{\multicolumn{3}{|c|}{ General }} & \multicolumn{3}{|c|}{ Ideal Granite } & \multicolumn{6}{|c|}{ Non-ideal Granite } \\
\hline & & & & \multicolumn{6}{|c|}{ First Order Markov Chain } & \multicolumn{3}{|c|}{$\begin{array}{l}\text { Second Order } \\
\text { Markov Chain }\end{array}$} \\
\hline $\begin{array}{l}\text { Number of } \\
\text { samples }\end{array}$ & \multicolumn{3}{|c|}{104} & \multicolumn{3}{|c|}{83} & \multicolumn{3}{|c|}{9} & \multicolumn{3}{|c|}{12} \\
\hline Minerals & 1 & 2 & 3 & 1 & 2 & 3 & 1 & 2 & 3 & 1 & 2 & 3 \\
\hline Average & 4.15 & 2.50 & 1.24 & 4.23 & 2.49 & 1.16 & 4.29 & 2.60 & 1.27 & 3.44 & 2.44 & 1.73 \\
\hline SDV & 0.90 & 0.41 & 0.61 & 0.90 & 0.44 & 0.61 & 0.64 & 0.32 & 0.43 & 0.79 & 0.26 & 0.58 \\
\hline \multirow{3}{*}{$\begin{array}{l}\text { Average of } \\
\text { within-group } \\
\text { SDV }\end{array}$} & \multirow{3}{*}{\multicolumn{3}{|c|}{1.51}} & \multicolumn{6}{|c|}{1.54} & \multirow{2}{*}{\multicolumn{3}{|c|}{1.29}} \\
\hline & & & & \multirow{2}{*}{\multicolumn{3}{|c|}{1.58}} & \multicolumn{3}{|c|}{1.20} & & & \\
\hline & & & & & & & \multicolumn{6}{|c|}{1.25} \\
\hline
\end{tabular}

see that the discrimination of ideal and non-ideal granites are not clearly separated in the distribution of standard deviation of the $\alpha$-value. This might indicate that the influence of viscosity of magma may not be significant on the near neighboring grains of minerals which are related to low-order Markov properties, but it might be significant on distant neighbors showing long term non-linear memory. This type of long term non-linear memory might be detectable using a multiscale approach as introduced in the current paper. Although more investigations are needed to understand the phenomena of randomness of crystallization of granites and the properties of magma, the results obtained from the current research might provide interesting statistical indexes for characterizing such type of behavior. The method proposed in this paper might be applicable to other types of sequences such as DNA or RNA sequences. Further investigations along these lines are worthwhile.

\section{Conclusions}

Two power-law models were proposed to quantify mineral sequences for scaling invariance analysis. The data from 104 mineral sequences previously used for ideal granite modeling were analyzed with the models and the results have shown that sequences of plagioclase, quartz and orthoclase of granite sample may show power-law relationships between clusters and voids of minerals and void lengths. It indicates that the clusters and voids of minerals in the sequence show scale invariance properties. The standard deviation of the exponents calculated for these three types of minerals from the power-law relationships fitted to the dataset has shown strong statistical correlations with the percentages of these minerals (positive correlation for orthoclase, and negative correlations for plagioclase and quartz). Therefore, standard deviation defined in the paper might be an effective index for characterizing the nature of randomness of crystallization of granites.

Acknowledgements. This research is sponsored by National Natural Science Foundation of China (40373003, 40502029 and 40638041), and China Scholarship Council. Thanks are due to Zhijing Wang who provided us with necessary literature and creative discussions. We are also thankful to our colleagues in the Geomatics Research Laboratory, York University for their timely help. E. Grunsky at the Geological Survey of Canada and an anonymous reviewer are thanked for their critical review of the paper and their constructive comments.

Edited by: A. Tarquis

Reviewed by: E. Grunsky and another referee

\section{References}

Banavar, J. R., Damuth, J., Maritan, A., et al.: Scaling in ecosystems and the linkage of macroecological laws, Phys. Rev. Lett., 98(6), 068104, doi:10.1103/PhysRevLett.98.068104, 2007.

Benguicui, L. and Blumenfeld-Lieberthal, E.: From lognormal distribution to power law: A new classification of the size distributions, Int. J. Modern Phys. C, 17(10), 1429-1436 2006.

Bohez, E. L. J.: Two level cluster analysis based on fractal dimension and iteratedfunction systems (IFS) for speech signal recognition, Circuits and Systems, The 1998 IEEE Asia-Pacific Conference on, Chiangmai, Thailand, 291-294, 1998. 
Cheng, Q.: Markov Processes and Discrete Multifractals, Math. Geology, 31, 445-468, 1999.

Cheng, Q.: Discrete Multifractals, Math. Geology, 29, 245-266, 1997.

Cheng, Q. and Agterberg, A. F.: Comparison between two types of multifractal modeling, Math. Geology, 28, 1001-1015, 1996.

Feder, J., Jossang, T., and Rosenquist, E.: Scaling behavior and cluster fractal dimension determined by light scattering from aggregating proteins, Phys. Rev. Lett., 53, 1403-1406, 1984.

Kim, J. S., Goh, K. I., Salvi, G., et al.: Fractality in complex networks: Critical and supercritical skeletons, Phys. Rev. E, 75(1), 016110, doi:10.1103/PhysRevE.75.016110, 2007.

Luo, Z. X. and Liu, C.: A validation of the fractal dimension of cloud boundaries, Geophys. Res. Lett., 34(3), L03808, doi:10.1029/2006GL028472, 2007.

Mandelbrot, B.: The Fractal Geometry of Nature, New York, W.H. Freeman, 1983.

Martin, H. G. and Goldenfeld, N.: On the origin and robustness of power-law species-area relationships in ecology, Proceedings of the national academy of sciences of the United States of America, 103(27), 10310-10315, 2006.

Mogilevsky, E. I. and Shilova, N. S.: Fractal-cluster analysis and small-scale structures of solar flares, Geomagnetism and Aeronomy, 46, 303-308, 2006.

Sasaki, M.: Statistical features of vein systems in the Hishikari epithermal gold deposit, Japan, Resource Geology, 56(1), 27-36, 2006.
Schultz, R. A., Okubo, C. H., and Wilkins, S. J.: Displacementlength scaling relations for faults on the terrestrial planets, J. Struct. Geology, 28(12), 2182-2193, 2006.

Varotsos, C., Assimakopoulos, M. N., and Efstathiou, M.: Technical Note: Long-term memory effect in the $\mathrm{CO}_{2}$ concentration at Mauna Loa, Atmos. Chem. Phys., 7, 629-634, 2007, http://www.atmos-chem-phys.net/7/629/2007/.

Verma, M. K., Manna, S., Banerjee, J., et al.: Universal scaling laws for large events in driven nonequilibrium systems, Europhysics Lett., 76(6), 1050-1056, 2006.

Vistelius, A. B.: On the Origin of Granodiorites of Mount Belaya (Kamchatka): An Experiment in Stochastic Modelling, Dokl. Akad. Nauk. SSSR (in Russian), 167, 1115-1118, 1966.

Vistelius, A. B.: Ideal Granite and its Properties: The Stochastic Model, J. Int. Assoc. Math. Geology, 4, 89-102, 1972.

Vistelius, A. B., Agterberg, F. P., Divi, R., and Hogarth, D. D.: A stochastic model for the crystalization and textural analysis of a fine-grained granitic stock near Meech Lake Gatineau Park, Quebec, Canada Geological Survey, Paper 81-21, Ottawa, 1983.

Vistelius, A. B. and Harbaugh, J. W.: Granitic Rocks of the Yosemite Valley and the Ideal Granite Model, J. Int. Assoc. Math. Geology, 12, 1-24, 1980.

Voss, R. F., Laibowitz, R. B., and Allessandrini, E. I.: Fractal (scaling) clusters in thin gold films near the percolation threshold, Phys. Rev. Lett., 49(19), 1441-1444, 1982. 